\title{
Neonatal and Adult ICU Ventilators to Provide Ventilation in Neonates, Infants, and Children: A Bench Model Study
}

\author{
Laurence Vignaux PhD, Lise Piquilloud MD, Pierre Tourneux MD, \\ Philippe Jolliet MD, and Peter C Rimensberger MD
}

\begin{abstract}
BACKGROUND: Using a bench test model, we investigated the hypothesis that neonatal and/or adult ventilators equipped with neonatal/pediatric modes currently do not reliably administer pressure support (PS) in neonatal or pediatric patient groups in either the absence or presence of air leaks. METHODS: PS was evaluated in $\mathbf{4}$ neonatal and 6 adult ventilators using a bench model to evaluate triggering, pressurization, and cycling in both the absence and presence of leaks. Delivered tidal volumes were also assessed. Three patients were simulated: a preterm infant (resistance $100 \mathrm{~cm} \mathrm{H} \mathrm{H}_{2} \mathrm{O} / \mathrm{L} / \mathrm{s}$, compliance $2 \mathrm{~mL} / \mathrm{cm} \mathrm{H}_{2} \mathrm{O}$, inspiratory time of the patient $\left[\mathrm{T}_{\mathrm{I}}\right] 400 \mathrm{~ms}$, inspiratory effort 1 and $2 \mathrm{~cm} \mathrm{H}_{2} \mathrm{O}$ ), a full-term infant (resistance $50 \mathrm{~cm} \mathrm{H} \mathrm{H}_{2} \mathrm{O} / \mathrm{L} / \mathrm{s}$, compliance

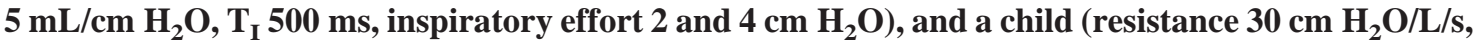
compliance $10 \mathrm{~mL} / \mathrm{cm} \mathrm{H}_{2} \mathrm{O}, \mathrm{T}_{\mathrm{I}} 600 \mathrm{~ms}$, inspiratory effort 5 and $10 \mathrm{~cm} \mathrm{H}_{2} \mathrm{O}$ ). Two PS levels were tested (10 and $15 \mathrm{~cm} \mathrm{H}_{2} \mathrm{O}$ ) with and without leaks and with and without the leak compensation algorithm activated. RESULTS: Without leaks, only 2 neonatal ventilators and one adult ventilator had trigger delays under a given predefined acceptable limit $\left(1 / 8 \mathrm{~T}_{\mathrm{I}}\right)$. Pressurization showed high variability between ventilators. Most ventilators showed $T_{I}$ in excess high enough to seriously impair patient-ventilator synchronization ( $>50 \%$ of the $T_{I}$ of the subject). In some ventilators, leaks led to autotriggering and impairment of ventilation performance, but the influence of leaks was generally lower in neonatal ventilators. When a noninvasive ventilation algorithm was available, this was partially corrected. In general, tidal volume was calculated too low by the ventilators in the presence of leaks; the noninvasive ventilation algorithm was able to correct this difference in only 2 adult ventilators. CONCLUSIONS: No ventilator performed equally well under all tested conditions for all explored parameters. However, neonatal ventilators tended to perform better in the presence of leaks. These findings emphasize the need to improve algorithms for assisted ventilation modes to better deal with situations of high airway resistance, low pulmonary compliance, and the presence of leaks. Key words: mechanical ventilators; ventilatory support; neonatal; pediatrics; intensive care units; equipment safety; respiration; artificial; models. [Respir Care 2014;59(10):1463-1475. (C) 2014 Daedalus Enterprises]
\end{abstract}

\section{Introduction}

Because of anatomic characteristics (small airway diameter) and specific respiratory mechanics (high resistance and low compliance) and because they often suffer from infectious airway diseases, neonates, infants, and small

\footnotetext{
Dr Vignaux is affiliated with the Cardio-Respiratory Physiotherapy Unit, Hôpital de La Tour, Meyrin, Switzerland. Drs Vignaux and Tourneux are affiliated with Peritox, EA 4284-Unité Mixte I01, L'Institut National de l'Environnement Industriel et des Risques, Université de Picardie Jules Verne, Amiens, France. At the time of this study, Dr Vignaux was affiliated the Adult Intensive Care Unit, University Hospital of Geneva,
}

children are prone to respiratory failure and possibly require respiratory support via mechanical ventilation despite their youth. Using assisted ventilation modes (during which the patient is given the opportunity to trigger the ventilator) is effective in increasing patients' comfort $^{1}$ and

\footnotetext{
Geneva, Switzerland. Drs Piquilloud and Jolliet are affiliated with the Adult Intensive Care and Burn Unit, University Hospital of Lausanne, Lausanne, Switzerland. Dr Tourneux is also affiliated with the Pediatric Intensive Care Unit, University Hospital North, Amiens, France. Dr Rimensberger is affiliated with the Neonatal and Pediatric Intensive Care Unit, University Hospital of Geneva, Geneva, Switzerland.
} 
limiting ventilator-induced diaphragmatic dysfunction ${ }^{2}$ compared with controlled ventilation modes. Assisted ventilation modes, particularly pressure support ventilation (PSV), have been increasingly used as an alternative to controlled mechanical ventilation. This change of practice is encouraged by the results of a meta-analysis showing that using various modes of assisted ventilation compared with pure controlled mechanical ventilation in neonates was associated with a shorter duration of mechanical ventilation. $^{3}$

\section{See the Related Editorial on Page 1606}

However, a major difficulty using assisted ventilation and especially PSV in small children (related to the use of uncuffed endotracheal tubes) is the presence of air leaks, which, as reported previously in adult studies, ${ }^{4,5}$ can be related to poor patient-ventilator synchrony. Specifically, significant air leaks are present in $\sim 70 \%$ of invasively ventilated neonates and are responsible for frequent autotriggering during assisted ventilation in this patient population. ${ }^{6}$

It was reported previously that during assisted pressure controlled ventilation (patient-triggered, pressure-targeted, time-cycled), adult ventilators equipped with a neonatal mode responded faster and more efficiently to a patient's effort compared with a specific neonatal ventilator, the Babylog 8000 (Dräger, Lübeck, Germany). ${ }^{7}$ As differences in ventilator technical performance can influence patientventilator synchrony during PSV, a better understanding of these differences would influence daily pediatric clinical practice regarding mechanical ventilation. Additionally, this knowledge could be of major interest when comparing improved patient-ventilator synchrony documented with neurally adjusted ventilatory assist. ${ }^{8,9}$

The purpose of this study was to investigate, using a bench model, the hypothesis that neonatal and/or adult ventilators equipped with neonatal/pediatric modes currently do not reliably administer pressure support (PS) in the absence or presence of air leaks.

Supplementary material related to this paper is available at http:// www.rcjournal.com.

The authors have disclosed no conflicts of interest.

Correspondence: Laurence Vignaux PhD, Cardio-Respiratory Physiotherapy Department, Hôpital de La Tour, 3 Avenue JD Maillard, 1217 Meyrin, Switzerland. E-mail: laurence.vignaux @latour.ch.

DOI: $10.4187 /$ respcare. 02540

\section{QUICK LOOK}

\section{Current knowledge}

Mechanical ventilation of the neonate is complicated by the requirement for small-diameter uncuffed endotracheal tubes and the presence of a variable leak. The performance of ventilators in the pressure support mode in this scenario is a technical challenge.

\section{What this paper contributes to our knowledge}

Neonatal ventilators performed better in the presence of high resistance, low compliance, and leaks than ventilators capable of adult and neonatal ventilation. No one ventilator performed optimally under all the test conditions. The use of the noninvasive algorithms on adult ventilators improved performance in this scenario except for one device.

\section{Methods}

\section{Ventilators}

Ten ICU ventilators, commonly available in Europe to ventilate neonates and small children, were tested in the Mechanical Ventilation Research Laboratory in the Adult Intensive Care Unit of the University Hospital of Geneva. Among these ventilators, there were 4 neonatal ventilators (SLE 5000, SLE Ltd, South Croydon, United Kingdom; Leoni Plus, Heinen + Löwenstein, Bad Ems, Germany; Babylog VN500, Dräger; Fabian, Acutronic Medical Systems AG, Hirzel, Switzerland) and 6 adult ventilators equipped with a neonatal/pediatric option (Servo-i, Maquet, Wayne, New Jersey; Evita XL NeoFlow, Dräger; Engström Carestation, GE Healthcare, Madison, Wisconsin; PB840, Covidien, Mansfield, Massachusetts; Avea, CareFusion, San Diego, California; G5, Hamilton Medical, Reno, Nevada). The main characteristics of these ventilators are summarized (see the supplementary materials at http://www.rcjournal.com).

\section{Bench Model}

A bench model derived from the one we used in our previous bench studies ${ }^{10-12}$ adapted to simulate specific neonatal, infant, and pediatric respiratory mechanics was used for this study (Fig. 1). Briefly, the model (Adult/Infant Training and Test Lung, Michigan Instruments, Grand Rapids, Michigan) consisted of 2 separate chambers linked by a rigid metal strip. The first chamber was connected to a driver ventilator (Evita 4, Dräger), which simulates patient inspiratory effort. ${ }^{10-12}$ The second chamber, a neonatal/pediatric compartment, was connected to the 


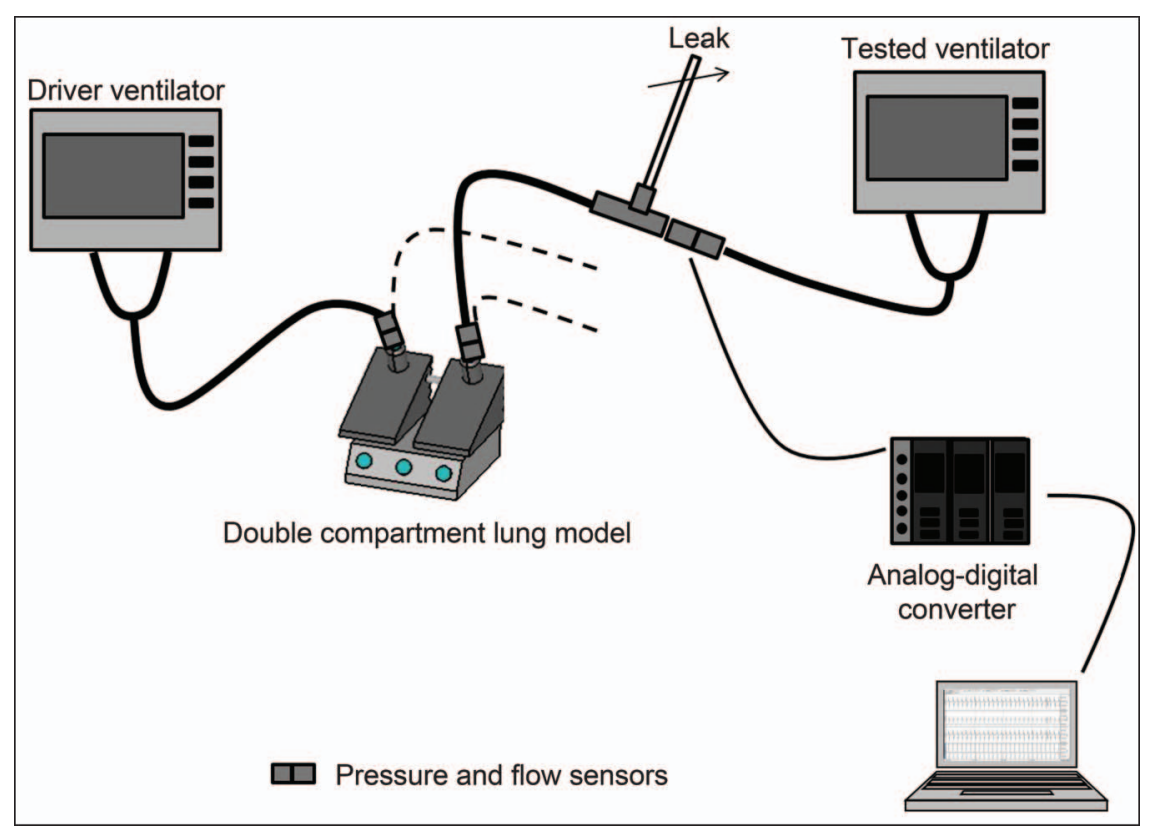

Fig. 1. Experimental setup. A neonatal/pediatric lung model was ventilated by a tested ventilator and triggered by a driver ventilator. Tidal volume was measured by the ventilator at the Y-piece and by a pneumotachograph at the lung compartment model. Different endotracheal tube leaks were simulated by open tubes of different lengths. Data were acquired online via an analog-to-digital converter and stored in a laptop computer for subsequent analysis.

ventilator being tested using a ventilator circuit equipped with a system designed to create intentional leaks (leak generator). Its total lung capacity was $200 \mathrm{~mL}$, its residual volume was $70 \mathrm{~mL}$, and its compliance could be adjusted from 1 to $15 \mathrm{~mL} / \mathrm{cm} \mathrm{H}_{2} \mathrm{O}$. The rigid metal strip placed between the 2 chambers allowed the transmission of the inspiratory effort from the first chamber to the second. The second chamber was free during expiration. The inspiratory effort generated by the driver ventilator was detected by the ventilator being tested, which, in response, initiated pressurization according to the chosen settings. To perform the measurements, 3 flow sensors and pressure transducers (Hamilton Medical) were inserted in the circuit between the driver ventilator and the lung model, between the lung model and the leak system, and between the leak system and the ventilator being tested. Data were recorded online using an analog-to-digital converter (MP100, Biopac Systems, Goleta, California), sampled at $500 \mathrm{~Hz}$, and stored in a laptop computer for subsequent analysis (AcqKnowledge software, Biopac Systems). All measurements were performed at an $\mathrm{F}_{\mathrm{IO}_{2}}$ of 0.21 .

\section{Measured Parameters}

The various parameters commonly used to assess ventilator performance during PSV were measured from the recorded curves (for detailed explanations, see the supplementary materials at http://www.rcjournal.com) ${ }^{12}$ : trigger delay to assess the ventilator response time, pressure-time product at $300 \mathrm{~ms}$ (PTP300) to assess global pressurization capacity, and inspiratory time in excess $\left(\mathrm{T}_{\mathrm{I}_{\mathrm{ex}}}\right)$ to assess cycling off. Delivered tidal volumes $\left(\mathrm{V}_{\mathrm{T}}\right)$ were also measured and compared with $\mathrm{V}_{\mathrm{T}}$ displayed by the machines. PTP300 was expressed as a percentage of an ideal PTP300 (illustrated in Fig. 2), defined as the PTP300 that would have been delivered if the delivered pressurization had immediately reached its maximum value (ie, no trigger delay and no rise time).

A maximum trigger delay of $100 \mathrm{~ms},{ }^{13,14}$ corresponding to $\sim 12.5 \%$ of the mean $\mathrm{T}_{\mathrm{I}}$ of $800 \mathrm{~ms},{ }^{4,15-17}$ is usually considered as acceptable in adult patients. In this study, inspiratory times of 400,500 , and $600 \mathrm{~ms}$ to simulate a preterm neonate, a full-term neonate, and a child were used, respectively (hereafter referred to as patient type). Therefore, we considered trigger delays of 50, 60, and $70 \mathrm{~ms}$ as acceptable upper limits for the 3 simulated patient types, respectively.

\section{Leaks}

Leaks were generated by using open silicone tubes (1.5-mm inner diameter) of 3 different lengths (one specific length for each simulated patient type) attached to a 3-way stopcock inserted between the Y-piece of the ventilator circuit and the lung model. The amount of leakage obtained was computed by subtracting the flow measured after leak generation from the flow measured before it. ${ }^{12}$ The leak flows obtained with a continuous PEEP of 


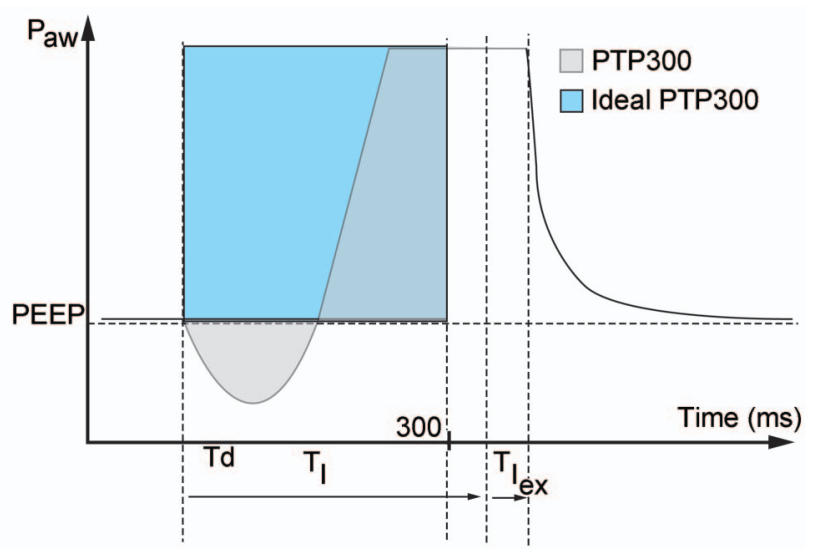

Fig. 2. Measured parameters. Trigger delay $(T d)$ is the time between the beginning of the inspiratory effort and the minimum value measured on the pressure curve during the triggering phase. The pressure-time product at $300 \mathrm{~ms}$ (PTP300) is expressed as a percentage of the ideal PTP, which corresponds to the PTP300 that would have been delivered if the pressurization delivered had immediately reached its maximum value (ie, no trigger delay and no rise time), and is represented by the rectangle. $T_{1}=$ inspiratory time of the patient (duration of inspiration by the patient [driver ventilator]). $T_{l_{\text {ex }}}=T_{1}$ in excess (duration of pressurization by the ventilator in excess of patient inspiratory duration). $\overline{\mathrm{P}}_{\mathrm{aw}}=$ airway pressure.

$5 \mathrm{~cm} \mathrm{H}_{2} \mathrm{O}$ for the 3 tested patient types were $0.6 \mathrm{~L} / \mathrm{min}$ $(0.01 \mathrm{~L} / \mathrm{s})$ for a resistance of $100 \mathrm{~cm} \mathrm{H}_{2} \mathrm{O} / \mathrm{L} / \mathrm{s}$ and a compliance of $2 \mathrm{~mL} / \mathrm{cm} \mathrm{H}_{2} \mathrm{O}$ with a tube of $343 \mathrm{~cm}, 1.2 \mathrm{~L} / \mathrm{min}$ $(0.02 \mathrm{~L} / \mathrm{s})$ for a resistance of $50 \mathrm{~cm} \mathrm{H}_{2} \mathrm{O} / \mathrm{L} / \mathrm{s}$ and a compliance of $5 \mathrm{~mL} / \mathrm{cm} \mathrm{H}_{2} \mathrm{O}$ with a tube of $172 \mathrm{~cm}$, and $2.4 \mathrm{~L} / \mathrm{min}(0.04 \mathrm{~L} / \mathrm{s})$ for a resistance of $30 \mathrm{~cm} \mathrm{H}_{2} \mathrm{O} / \mathrm{L} / \mathrm{s}$ and a compliance of $10 \mathrm{~mL} / \mathrm{cm} \mathrm{H}_{2} \mathrm{O}$ with a tube of $95 \mathrm{~cm}$.

\section{Experiment Protocol}

The driver ventilator was set in airway pressure release ventilation mode. Thus, the inspiratory effort generated was equal to the set pressure above PEEP. ${ }^{10-12}$ The baseline breathing frequency was 20 breaths $/ \mathrm{min}$. In the case of air trapping related to delayed cycling, the breathing frequency was decreased to allow complete expiration, which was assessed using visualization of the flow curve (expiration was considered complete when the flow curve came back to 0 before the start of the next inspiratory effort).

The various ventilators were tested with the 3 simulated patient types. Preterm infant settings were: resistance $100 \mathrm{~cm} \mathrm{H}_{2} \mathrm{O} / \mathrm{L} / \mathrm{s}$, compliance $2 \mathrm{~mL} / \mathrm{cm} \mathrm{H}_{2} \mathrm{O}, \mathrm{T}_{\mathrm{I}} 400 \mathrm{~ms}$, inspiratory efforts 1 and $2 \mathrm{~cm} \mathrm{H}_{2} \mathrm{O}$ (R100C2). Full-term infant settings were: resistance $50 \mathrm{~cm} \mathrm{H}_{2} \mathrm{O} / \mathrm{L} / \mathrm{s}$, compliance $5 \mathrm{~mL} / \mathrm{cm} \mathrm{H}_{2} \mathrm{O}, \mathrm{T}_{\mathrm{I}} 500 \mathrm{~ms}$, inspiratory efforts 2 and $4 \mathrm{~cm} \mathrm{H}_{2} \mathrm{O}$ (R50C5). Child settings were: resistance $30 \mathrm{~cm} \mathrm{H}_{2} \mathrm{O} / \mathrm{L} / \mathrm{s}$, compliance $10 \mathrm{~mL} / \mathrm{cm} \mathrm{H}_{2} \mathrm{O}, \mathrm{T}_{\mathrm{I}} 600 \mathrm{~ms}$, inspiratory efforts 5 and $10 \mathrm{~cm} \mathrm{H}_{2} \mathrm{O}$ (R30C10). As the amplitude of inspiratory efforts varies in children in general ${ }^{18,19}$ and can, under some circumstances such as during sleep or with small infants, be very low, ${ }^{20-22}$ we chose to simulate this as well. Neonatal options of the Fabian and Evita XL NeoFlow ventilators were tested with R100C2, and R50C5; pediatric options of the same ventilators were tested with R50C5 and R30C10.

Each ventilator was tested in PSV mode with the following settings: maximum sensitivity inspiratory flow trigger while avoiding autotriggering, PEEP $5 \mathrm{~cm} \mathrm{H}_{2} \mathrm{O}$, PS levels 10 and $15 \mathrm{~cm} \mathrm{H}_{2} \mathrm{O}$, backup ventilation deactivated, expiratory trigger setting (ETS) at $15 \%$ of the peak inspiratory flow (except the Leoni Plus ventilator, which has a non-modifiable ETS of 25\%). If adjustable, the maximum $T_{I}$ was set to the highest value possible to avoid time-based cycling.

To test the influence of the leaks on ventilation performance, tests were carried out while applying the 3 following leakage scenarios: (1) in the absence of leaks and with the ventilator leak compensation algorithm or noninvasive ventilation (NIV) algorithm deactivated, (2) in the presence of leaks and with the NIV algorithm (which should theoretically compensate for the presence of leaks) deactivated, and (3) in the presence of leaks and with the NIV algorithm activated. For each tested condition (patient type plus leakage scenario), 2 min were recorded. Between 2 different conditions, a washout period of $2 \mathrm{~min}$ was observed.

\section{Statistical Analysis}

For each tested condition, 10 consecutive, interpretable, and triggered respiratory cycles (starting from the second recorded cycle) were considered for the analyses. All results are expressed as mean $\pm \mathrm{SD}$.

For each simulated patient type, the measured parameters were compared between the different respiration scenarios (with or without leaks and with or without the NIV algorithm activated) by repeated measures analysis of variance, followed by a pairwise multiple comparison procedure for post hoc analysis (Student-Newman-Keuls method) when analysis of variance was statistically significant.

All statistical analyses were performed using SigmaStat 2.0 (Systat, San Jose, California). $P<.05$ was considered statistically significant. Only data that had a difference of $>10 \%$ in absolute value was considered clinically relevant. Only clinically relevant and statistically significant data are provided in the tables and figures and considered for discussion. 


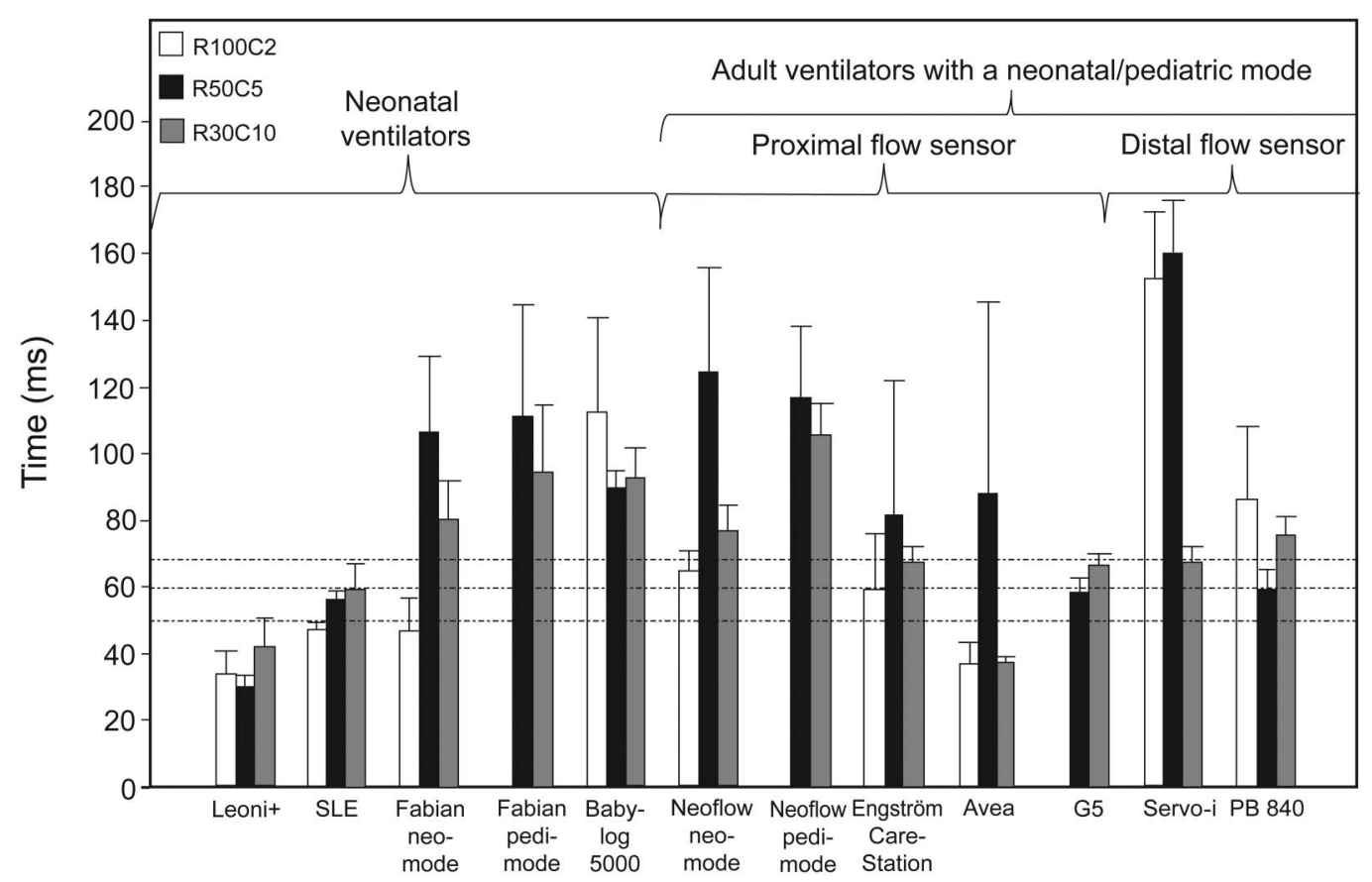

Fig. 3. Trigger delay with the 10 ventilators tested with 3 different types of patients: a preterm infant (resistance $100 \mathrm{~cm} \mathrm{H} \mathrm{H}_{2} \mathrm{O} / \mathrm{L} / \mathrm{s}$, compliance $2 \mathrm{~mL} / \mathrm{cm} \mathrm{H}_{2} \mathrm{O}$, inspiratory time [ $\left.\mathrm{T}_{1}\right] 400 \mathrm{~ms}$, inspiratory effort 1 and $2 \mathrm{~cm} \mathrm{H}_{2} \mathrm{O}$ [R100C2]), a full-term infant (resistance $50 \mathrm{~cm} \mathrm{H} \mathrm{H}_{2} \mathrm{O} / \mathrm{L} / \mathrm{s}$, compliance $5 \mathrm{~mL} / \mathrm{cm} \mathrm{H}_{2} \mathrm{O}, \mathrm{T}_{1} 500 \mathrm{~ms}$, inspiratory effort 2 and $4 \mathrm{~cm} \mathrm{H}_{2} \mathrm{O}$ [R50C5]), and a child (resistance $30 \mathrm{~cm} \mathrm{H} / \mathrm{O} / \mathrm{L} / \mathrm{s}$, compliance $10 \mathrm{~mL} / \mathrm{cm} \mathrm{H}_{2} \mathrm{O}, \mathrm{T}_{1} 600 \mathrm{~ms}$, inspiratory effort 5 and $10 \mathrm{~cm} \mathrm{H}_{2} \mathrm{O}$ [R30C10]). Two pressure support levels (10 and $\left.15 \mathrm{~cm} \mathrm{H}_{2} \mathrm{O}\right)$ were tested; results are pooled. Histogram bars are mean \pm SD.

\section{Results}

\section{Ventilation Performance in the Absence of Leaks}

Triggering: Trigger Delays. For simulated neonatal ventilation, 3 neonatal ventilators (Leoni Plus, SLE 5000, and Fabian) and one adult ventilator (Avea) had trigger delays below the predefined acceptable limit (Fig. 3). For simulated child ventilation, 2 neonatal ventilators (Leoni Plus and SLE 5000) and one adult ventilator (G5) had trigger delays below the predefined acceptable limits. For some ventilators, trigger delays were very different between the various simulated patient types.

Pressurization: PTP300. Pressurization capacities were very different depending on the ventilator and simulated patient type, ranging from 15\% (PB840) to 70\% (Engström Carestation and Fabian in neonatal mode) of ideal PTP300 (Fig. 4). The highest global PTP300 values were achieved by 2 adult ventilators (Engström Carestation and Avea) and one neonatal ventilator (Fabian). Most of the ventilators, with the exception of Babylog VN500, Servo-i, and PB840, showed reduced pressurization capacity when the simulated patient type's age was increased (ie, compliance increasing, resistance decreasing, and inspiratory effort increasing). Except for the G5 and Engström Carestation, PTP300 values were clearly below $50 \%$ of the ideal PTP300 in at least one of the 3 simulated patient types.

Cycling: $\mathbf{T}_{\mathbf{I}_{\mathrm{ex}}}$. Most ventilators had a very high $\mathrm{T}_{\mathrm{I}_{\mathrm{ex}}}$ (ie, $>50 \%$ of the patient's $\mathrm{T}_{\mathrm{I}}$ ). The $\mathrm{T}_{\mathrm{I}_{\mathrm{ex}}}$ sometimes varied a lot for a single ventilator between various simulated patient types (Fig. 5). Three ventilators (Babylog VN500, G5, and Servo-i) had a clearly lower $\mathrm{T}_{\mathrm{I}_{\mathrm{ex}}}$ compared with the others. In contrast, 4 ventilators (SLE 5000, Fabian in neonatal mode, PB840, and Avea) had a $\mathrm{T}_{\mathrm{I}_{\mathrm{ex}}}$ that was $>100 \%$ of the $\mathrm{T}_{\mathrm{I}}$, meaning that the ventilator-delivered pressurization lasted more than twice the patient's $\mathrm{T}_{\mathrm{I}}$, in at least one of the simulated patient types.

\section{Influence of Leaks}

Autotriggering. Introducing a leak into the circuit led to autotriggering in almost all ventilators except the Babylog VN500 and Fabian. For the Leoni Plus and G5, increasing the inspiratory trigger only slightly (from 0.1 to $0.2 \mathrm{~L} / \mathrm{min}$ and from 0.5 to $1 \mathrm{~L} / \mathrm{min}$, respectively) solved the problem. Activating the NIV algorithm when available also corrected the problem, except for the Avea. 


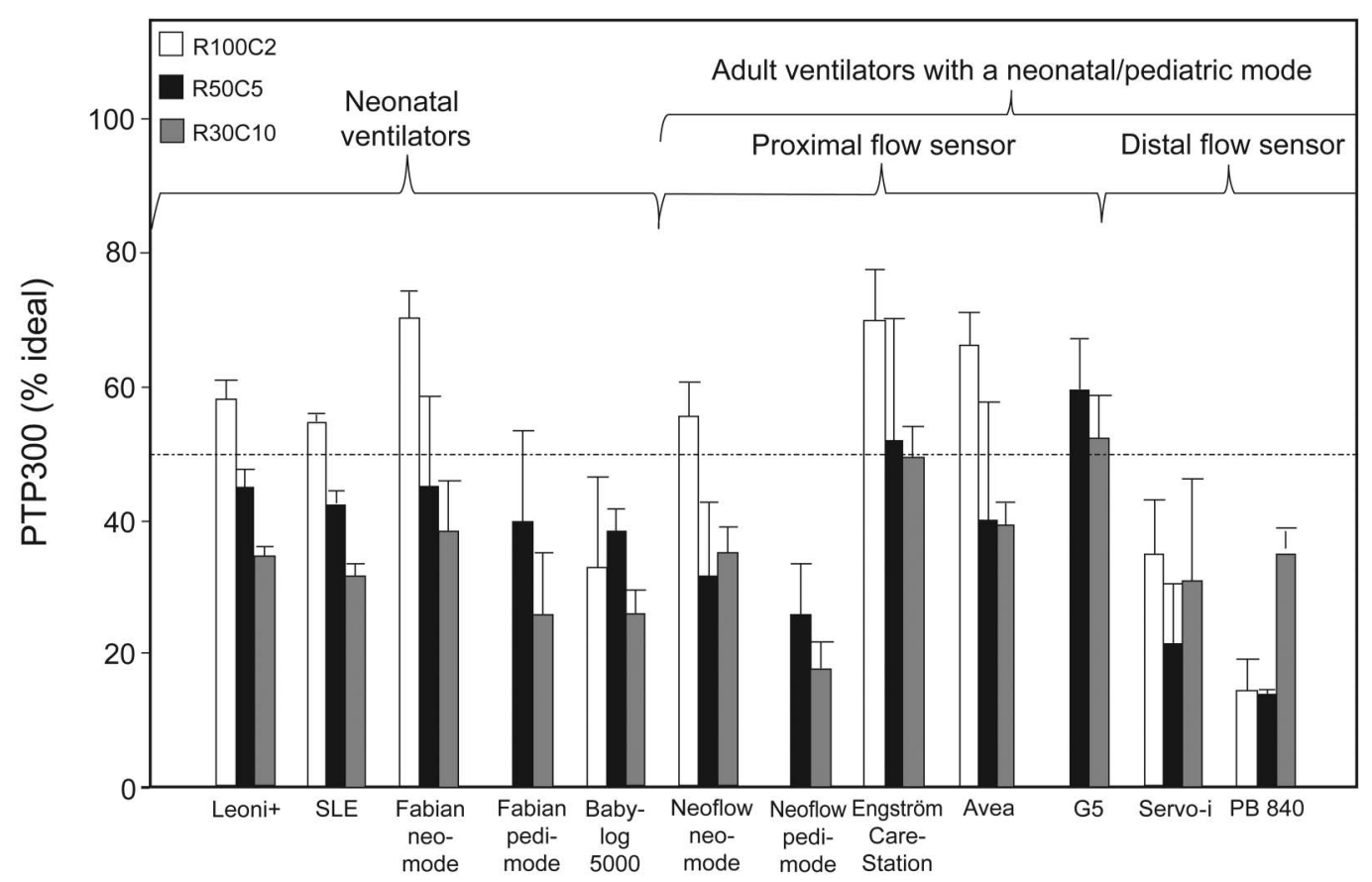

Fig. 4. Pressure-time product at $300 \mathrm{~ms}$ (PTP300) with the 10 ventilators tested with 3 different patient types: a preterm infant (resistance $100 \mathrm{~cm} \mathrm{H} \mathrm{H}_{2} \mathrm{O} / \mathrm{L} / \mathrm{s}$, compliance $2 \mathrm{~mL} / \mathrm{cm} \mathrm{H}_{2} \mathrm{O}$, inspiratory time [ $\left.\mathrm{T}_{1}\right] 400 \mathrm{~ms}$, inspiratory effort 1 and $2 \mathrm{~cm} \mathrm{H}_{2} \mathrm{O}$ [R100C2]), a full-term infant (resistance $50 \mathrm{~cm} \mathrm{H} \mathrm{m}_{2} \mathrm{O} / \mathrm{L} / \mathrm{s}$, compliance $5 \mathrm{~mL} / \mathrm{cm} \mathrm{H}_{2} \mathrm{O}, \mathrm{T}_{1} 500 \mathrm{~ms}$, inspiratory effort 2 and $4 \mathrm{~cm} \mathrm{H}_{2} \mathrm{O}$ [R50C5]), and a child (resistance $30 \mathrm{~cm} \mathrm{H} \mathrm{H}_{2} \mathrm{O} / \mathrm{L} / \mathrm{s}$, compliance $10 \mathrm{~mL} / \mathrm{cm} \mathrm{H}_{2} \mathrm{O}, \mathrm{T}_{1} 600 \mathrm{~ms}$, inspiratory effort 5 and $10 \mathrm{~cm} \mathrm{H}_{2} \mathrm{O}$ [R30C10]). Two pressure support levels (10 and $15 \mathrm{~cm} \mathrm{H}_{2} \mathrm{O}$ ) were tested; results are pooled. The limit of $100 \mathrm{~ms}$ is generally recommended in adults ${ }^{4,17}$ for a mean $\mathrm{T}_{1}$ of $800 \mathrm{~ms}$. Histogram bars are mean $\pm \mathrm{SD}$.

Trigger Delay. Introducing a leak substantially increased trigger delay for the Leoni Plus, Evita XL NeoFlow, Engström Carestation, and Avea, namely, for one neonatal ventilator and 4 adult ventilators (Fig. 6). Activation of the NIV algorithm allowed complete or partial compensation for the impairment in only 2 adult ventilators (Evita XL NeoFlow with pediatric mode and Engström Carestation). Activating the Servo-i NIV algorithm induced a major increase in trigger delay (26\%).

Pressurization. No PTP300\% variation was noted with the 4 neonatal ventilators tested when a leak was added in the circuit (Fig. 7). In contrast, 2 adult ventilators showed a significant reduction in PTP300\% (Evita XL NeoFlow with pediatric mode and Avea). The NIV algorithm compensated for the pressurization loss only for the Evita XL NeoFlow. Additionally, the pressurization capacity was significantly lower in the presence of leaks and with the NIV algorithm activated for the Servo-i and PB840 compared with the scenarios of (1) in the absence of leaks and with the ventilator leak compensation algorithm or NIV algorithm deactivated and (2) in the presence of leaks and with the NIV algorithm deactivated. No variations of pressurization capacity between the simulated patient types were observed for the G5. Note that the G5 was not tested for the R100C 2 simulation, as, at the time this bench test was performed, this ventilator was not approved to ventilate children $<3 \mathrm{~kg}$ of body weight.

Cycling. The presence of leaks increased the $T_{I_{e x}}$ in all ventilators except the Fabian in neonatal mode, Babylog VN500, and Evita XL NeoFlow in neonatal mode (Fig. 8). The $\mathrm{T}_{\mathrm{I}_{\mathrm{ex}}}$ was clearly $>100 \%$ in 3 adult ventilators (Engström Carestation, PB840, and Avea) and one neonatal ventilator (SLE 5000) in the presence of leaks. The only 2 ventilators for which the $\mathrm{T}_{\mathrm{I}_{\mathrm{ex}}}$ was $<50 \%$ in the presence of leaks were the Evita XL NeoFlow and Babylog VN500. Using the NIV algorithm reduced the impairment of $T_{I_{e x}}$ only for the Engström Carestation (partial correction), Servo-i (partial correction), and PB840 (total correction).

\section{Volumes}

In the absence of leaks, the difference between the displayed and measured $\mathrm{V}_{\mathrm{T}}$ was in the range of $\pm 10 \%$ for all tested ventilators except the Evita XL NeoFlow in neonatal mode, Avea, and Servo-i (Table 1). Concerning the technological characteristics of the ventilators (see the supplementary materials at http://www.rcjournal.com), our measurements showed no differences in $\mathrm{V}_{\mathrm{T}}$ accuracy between ventilators equipped or not with a proximal flow 


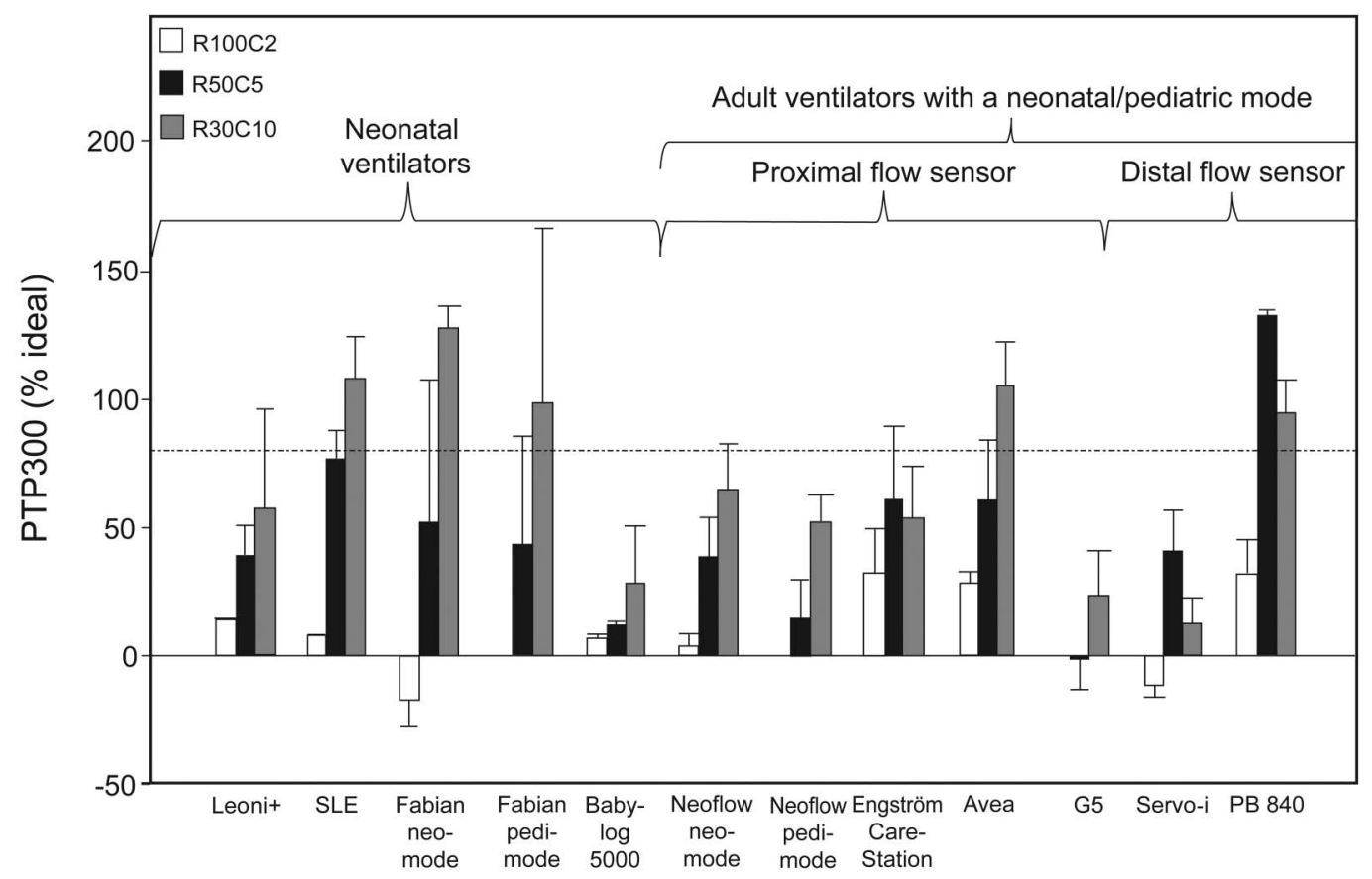

Fig. 5. Inspiratory time in excess with the 10 ventilators tested with 3 different patient types : a preterm infant (resistance $100 \mathrm{~cm} \mathrm{H}_{2} \mathrm{O} / \mathrm{L} / \mathrm{s}$, compliance $2 \mathrm{~mL} / \mathrm{cm} \mathrm{H}_{2} \mathrm{O}$, inspiratory time [ $\left.\mathrm{T}_{1}\right] 400 \mathrm{~ms}$, inspiratory effort 1 and $2 \mathrm{~cm} \mathrm{H}_{2} \mathrm{O}$ [R100C2]), a full-term infant (resistance $50 \mathrm{~cm} \mathrm{H} \mathrm{H}_{2} \mathrm{O} /$ $\mathrm{L} / \mathrm{s}$, compliance $5 \mathrm{~mL} / \mathrm{cm} \mathrm{H}_{2} \mathrm{O}, \mathrm{T}_{1} 500 \mathrm{~ms}$, inspiratory effort 2 and $4 \mathrm{~cm} \mathrm{H} \mathrm{H}_{2} \mathrm{O}$ [R50C5]), and a child (resistance $30 \mathrm{~cm} \mathrm{H} \mathrm{H}_{2} \mathrm{O} / \mathrm{L} / \mathrm{s}, \mathrm{compliance}$ $10 \mathrm{~mL} / \mathrm{cm} \mathrm{H}_{2} \mathrm{O}, \mathrm{T}_{1} 600 \mathrm{~ms}$, inspiratory effort 5 and $10 \mathrm{~cm} \mathrm{H}_{2} \mathrm{O}$ [R30C10]). Two pressure support levels (10 and $\left.15 \mathrm{~cm} \mathrm{H}_{2} \mathrm{O}\right)$ were tested; results are pooled. The limit of $100 \mathrm{~ms}$ is generally recommended in adults ${ }^{4,17}$ for a mean $\mathrm{T}_{1}$ of 800 ms. Note that the Leoni Plus could be tested only with an expiratory trigger setting of $25 \%$. Histogram bars are mean \pm SD.

sensor. Also, we saw no relevant differences in flow measurement accuracy between flow sensors using the hotwire or pressure differential technique. In the presence of leaks, this difference between the displayed and measured $\mathrm{V}_{\mathrm{T}}$ became much more important. In this case, most of the ventilators displayed a value that was too low for the measured $\mathrm{V}_{\mathrm{T}}$.

Activation of the NIV algorithm did not correct the differences between the measured and displayed $\mathrm{V}_{\mathrm{T}}$ for the Evita XL NeoFlow and G5. In contrast, activating the NIV mode efficiently corrected the problem for both the Engström Carestation and PB840. Under some conditions, the PB840 and Servo-i displayed a value that was too high for the effective $V_{T}$ when the NIV algorithm was activated.

\section{Discussion}

Our results show that, during the PS mode, under different bench testing conditions, the performance of the various ventilators differed drastically with regard to trigger delay, pressurization capacity, and cycling. This applied to ventilators designed primarily for neonates and children as well as adult ventilators adapted to ventilate small children. Some of the ventilators tested performed well in one or two of the measured parameters, but unfortunately, we could not identify one or several optimal ventilators that performed well for all the tested criteria. This was particularly true when the ventilators' performance was assessed in the presence of leaks.

On the basis of our measurements, we could not find any solid argument that would speak against the use of common adult ventilators in the neonatal field. However, several items have to be discussed in more detail.

\section{Ventilation Performance in the Absence of Leaks}

Trigger. A prolonged trigger delay results in a large amount of time during which the patient does not receive ventilator-delivered assistance. Prolonged trigger delays observed with some of the tested ventilators might be of major concern for neonatal and pediatric ventilation. In a previous bench study, ${ }^{7}$ a trigger delay $<100 \mathrm{~ms}$ was reported for 6 tested ventilators, with values close to $60 \mathrm{~ms}$ for 2 ventilators (Avea and Engström Carestation). Our results obtained under similar respiratory mechanics test conditions simulating a preterm infant (R100C2) are in line with these findings. In our bench test, the new Baby$\log$ VN500 had a trigger delay of $110 \pm 30 \mathrm{~ms}$. This value is similar to the trigger delays found by Marchese et $\mathrm{al}^{7}$ in 


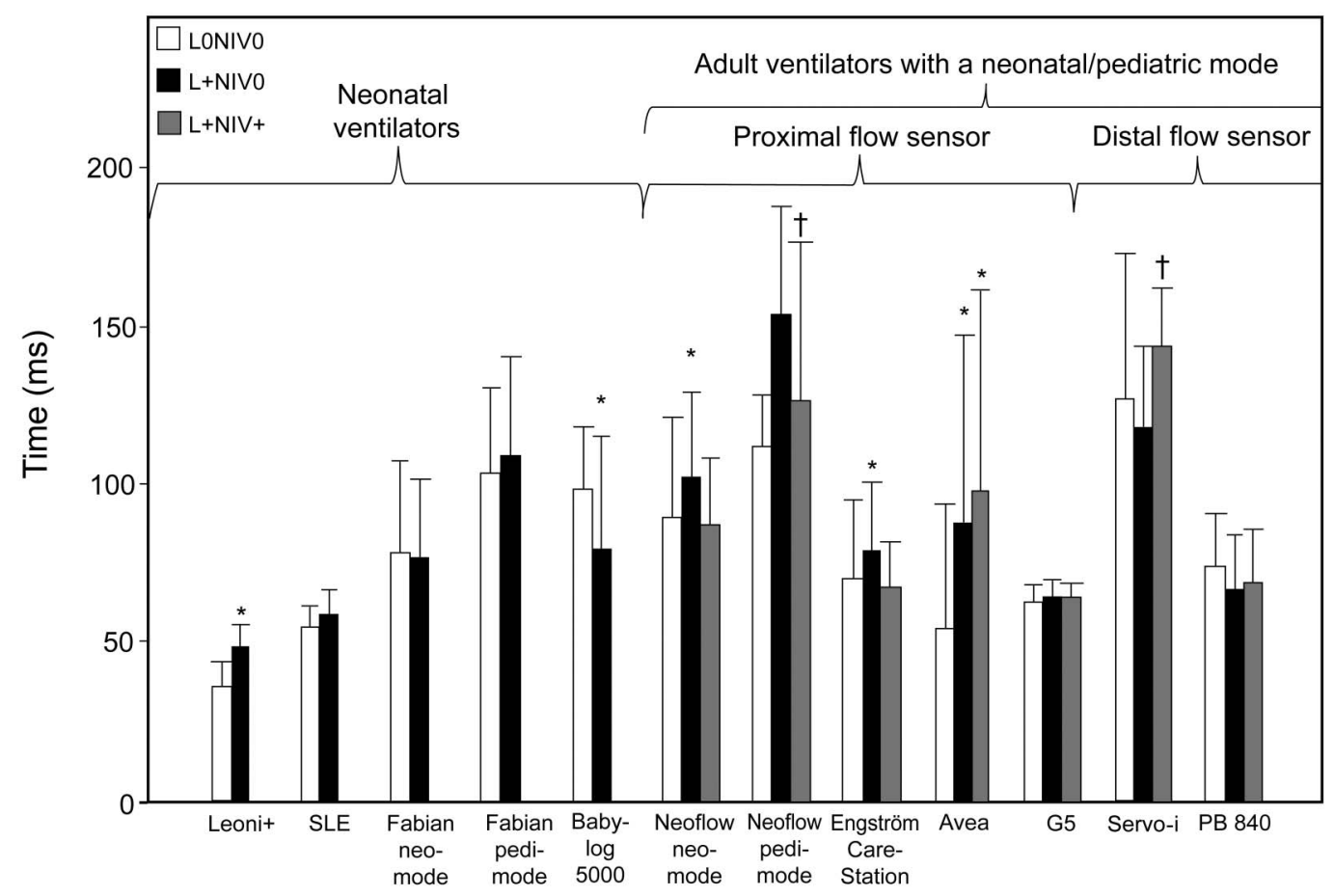

Fig. 6. Trigger delays and leaks. Inspiratory time with the 10 ventilators tested under 3 conditions: in the absence of leaks and with the noninvasive ventilation (NIV) algorithm deactivated (LONIV0), in the presence of leaks and with the NIV algorithm deactivated (L + NIV0), and in the presence of leaks and with the NIV algorithm activated $(L+N I V+)$. All results are pooled. Histogram bars are mean \pm SD. ${ }^{*}<.05$ vs LONIVO; † $P<.05$ vs L+NIVO (analysis of variance).

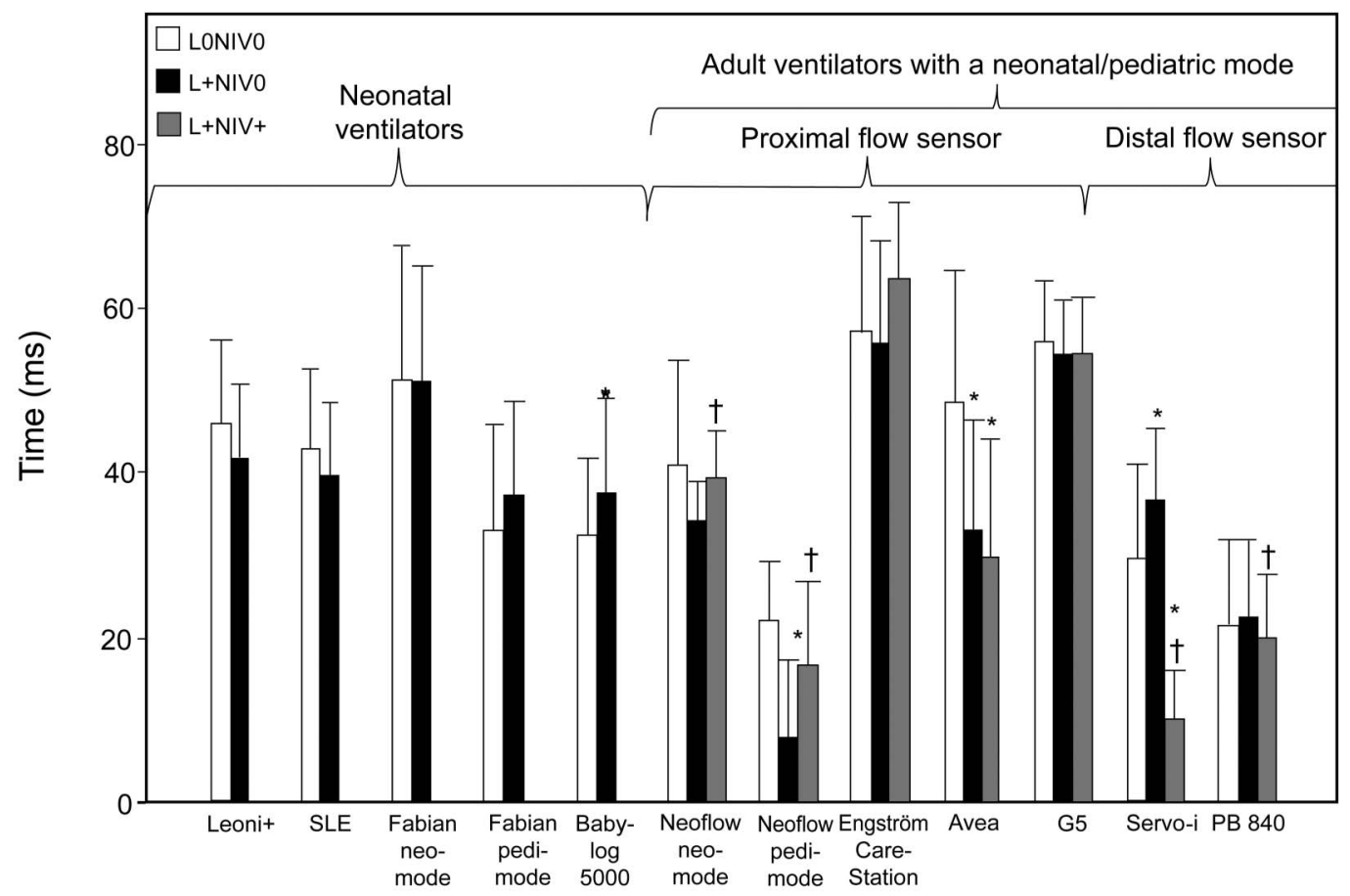

Fig. 7. Pressure-time product at $300 \mathrm{~ms}$ (PTP300) and leaks. Trigger delay with the 10 ventilators tested under 3 conditions: in the absence of leaks and with the NIV algorithm deactivated (LONIV0), in the presence of leaks and with the NIV algorithm deactivated (L+NIV0), and in the presence of leaks and with the NIV algorithm activated $(\mathrm{L}+\mathrm{NIV}+)$. All results are pooled. Histogram bars mean $\pm \mathrm{SD}$. ${ }^{*} P<.05$ vs LONIVO; $†<.05$ vs L+NIVO (analysis of variance). 


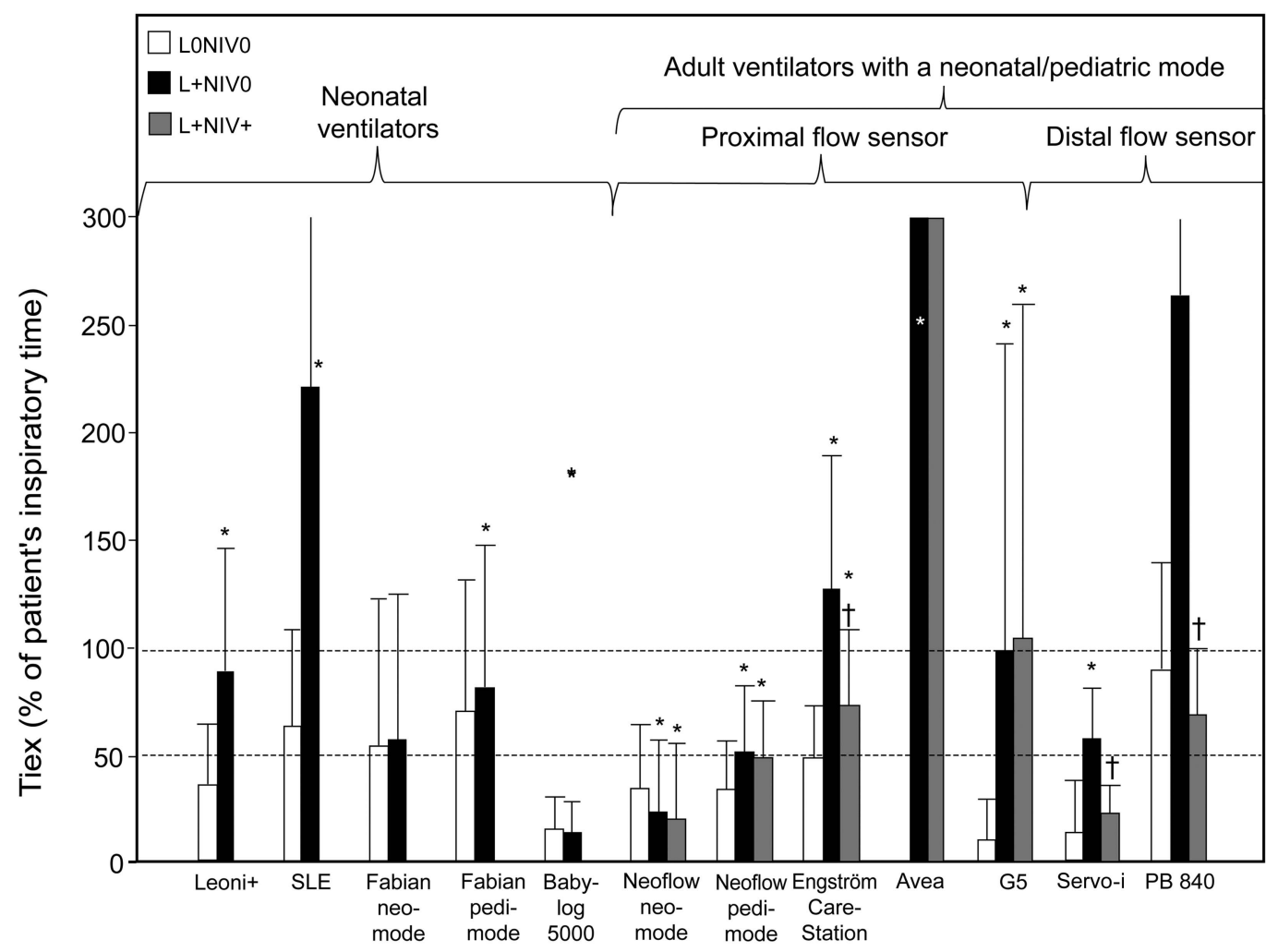

Fig. 8. Inspiratory time in excess $\left(T_{l_{e x}}\right)$ with the 10 ventilators tested under 3 conditions: in the absence of leaks and with the NIV algorithm deactivated (LONIV0), in the presence of leaks and with the NIV algorithm deactivated ( $L+N I V 0)$, and in the presence of leaks and with the NIV algorithm activated $(\mathrm{L}+\mathrm{NIV}+)$. All results are pooled. Histogram bars mean $\pm \mathrm{SD} .{ }^{*} P<.05$ vs LONIV0; $P<<.05$ vs $L+\mathrm{NIV0}$ (analysis of variance). Note that the Leoni Plus could be tested only with an expiratory trigger setting of $25 \%$.

similar simulated patient types with the Babylog 8000. In contrast, a shorter trigger delay of $75 \mathrm{~ms}$ was reported when the Babylog 8000 was used in neonates. ${ }^{23}$ This might suggest that our bench test could have slightly underestimated the ventilation performance of the ventilators tested, possibly because of the difficulty in accurately simulating real pediatric patients' inspiratory efforts. However, in our bench test, the trigger delays measured for the Servo-i were in line with the values reported in clinical settings. ${ }^{8,9,24}$

Pressurization. In the pediatric literature, there are a striking lack of data on the possible clinical impact of pressurization capacities of mechanical ventilators. Theoretically, limited pressurization capacities might be responsible for a discrepancy between a patient's inspiratory demand and the pressure delivered by the machine, which could be responsible for an increased work of breathing or for generating patient-ventilator asynchronies. However, no clinical data are currently available concerning this topic in the pediatric population.

Cycling. In the presence of late cycling, patients often fight against their ventilators and actively recruit their expiratory muscles, thus increasing the risk of significant leaks. ${ }^{25}$ On the other hand, the occurrence of premature cycling decreases the time available to deliver respiratory assistance, which might lead, at a given level of PS, to a lower $\mathrm{V}_{\mathrm{T}}$ than expected. Both conditions might increase a patient's work of breathing. ${ }^{26}$ Optimizing ETS should theoretically reduce the occurrence of cycling asynchronies. However, ETS optimization can be difficult at the bedside, as the respiratory mechanics might change rapidly depending on the deterioration or improvement of the patient's condition, and as the intermittent occurrence of a leak can influence expiratory asynchrony. This calls the use of cycling criteria in daily practice into question.

It must also be emphasized that the relatively good results regarding cycling $\left(\mathrm{T}_{\mathrm{I}_{\mathrm{ex}}} \leq 50 \%\right)$ observed with 4 of the ventilators (Babylog VN500, Evita XL NeoFlow in pediatric mode, G5, and Servo-i) might be counterbalanced by an increased risk of unwanted premature cycling, as reported previously by Beck et $\mathrm{al}^{23}$ for the Babylog 8000 and by our group for the Servo-i. ${ }^{24}$

\section{Ventilation Performance in the Presence of Leaks}

Trigger. Similar to what was reported previously in adult bench tests, ${ }^{12,15}$ NIV algorithms significantly reduced au- 
ICU Ventilators for NeONATes, Infants, AND ChildRen

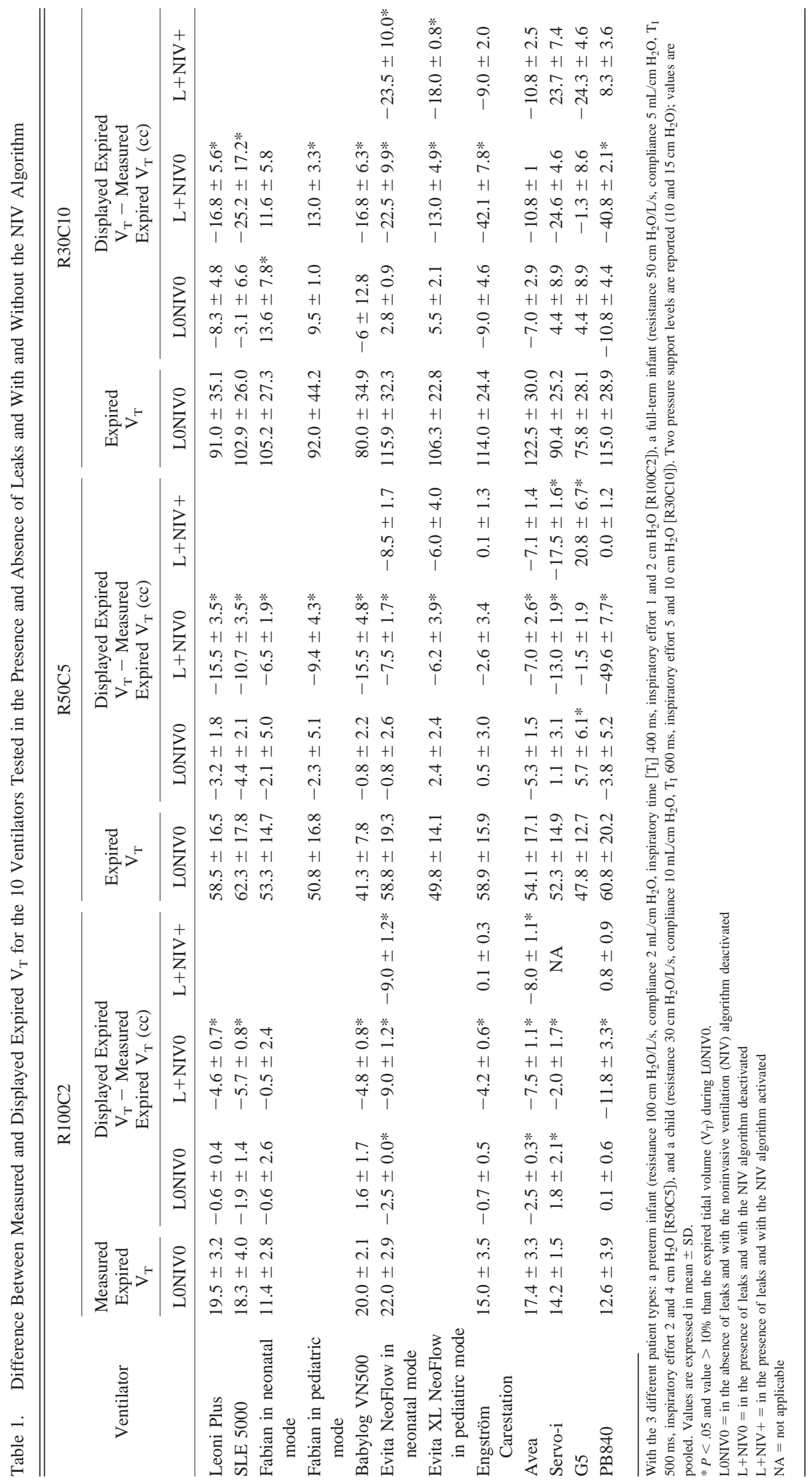


totriggering related to leaks. Interestingly, of the neonatal ventilators, only the SLE 5000 required a significant increase in the flow trigger threshold (less sensitive trigger) to overcome this phenomenon. This can probably be explained by the fact that a leak compensation algorithm is activated by default in neonatal devices (see the supplementary materials at http://www.rcjournal.com).

In adult bench tests, it was reported previously that the trigger delay increased to unacceptable values in the presence of leaks. ${ }^{12,15}$ In contrast, in our neonatal/pediatric bench test, this increase in trigger delay was globally lower and not systematic. Leaks did not cause major trigger delay increases in neonatal ventilators or in 2 of the adult ventilators. When considering adult ventilators, in the presence of leaks, 3 ventilators showed a significant increase in trigger delays (Evita XL NeoFlow, Engström Carestation, and Avea) compared with the absence of leaks. Among these 3 ventilators, activating the NIV mode corrected the impairment in only 2 of the ventilators (Evita XL NeoFlow and Engström Carestation). Surprisingly, but as reported previously in an adult bench test, ${ }^{12}$ the Servo-i showed a higher trigger delay when activating the NIV algorithm in the presence of leaks. The measured trigger delay in this scenario (in the presence of leaks and with the NIV algorithm activated) is similar to values reported previously in a clinical study performed in infants and children by our group. ${ }^{24}$

Pressurization. For some adult ventilators, pressurization was impaired in the presence of leaks either with or without the NIV algorithm activated. We hypothesize that this could lead to situations of underassistance when adult ventilators are used to ventilate small infants. In contrast, no change in pressurization was observed in the presence of leaks for the 4 neonatal ventilators tested.

Cycling. In our bench test, as found previously in other studies, ${ }^{17,27}$ we found that the $\mathrm{T}_{\mathrm{I}_{\mathrm{ex}}}$ was higher in the presence of leaks. As an increased $\mathrm{T}_{\mathrm{I}_{\mathrm{ex}}}$ is associated with an increased incidence of late cycling and of ineffective efforts, $5,18 \mathrm{a} \mathrm{T}_{\mathrm{I}_{\mathrm{ex}}}$ that is $>100 \%$ of the $\mathrm{T}_{\mathrm{I}}$, as we observed in one neonatal and 3 adult ventilators, is worrying. The specific NIV algorithm, included by default, in neonatal ventilators is of interest, although it showed poor ventilation performance in one ventilator (Avea).

\section{Volume Measurement Accuracy}

Absence of Leaks. In baseline respiration scenarios, for all ventilators in almost all simulated patient types, there were no significant differences between the displayed and measured $\mathrm{V}_{\mathrm{T}}$. To accurately measure $\mathrm{V}_{\mathrm{T}}$, especially in neonates, proximal flow sensors have been strongly advocated for many years. ${ }^{28,29}$ Interestingly, our measurements showed no differences in $\mathrm{V}_{\mathrm{T}}$ accuracy between different flow measurement techniques (distal or proximal flow sensor, hotwire or pressure differential technique). However, this may possibly not be applicable to cases with very severe compliance impairment or high airway resistance, as these formed no part of our bench test.

Presence of Leaks. Globally, in the presence of leaks and with the NIV algorithm deactivated, the ventilators tested tended to display a value that was too low for the $\mathrm{V}_{\mathrm{T}}$ effectively delivered to the patient, which could lead to the delivery of a higher assist than expected and even to situations of overassistance. Most (but not all) NIV algorithms corrected this problem. As leaks are often present during neonatal and pediatric invasive ventilation, activation of NIV algorithms is suggested, provided that the algorithm of the ventilator performs well.

\section{Clinical Implications}

Our bench test suggests that the ventilators used to deliver PSV to the pediatric population do not perform well in all circumstances regarding trigger delays, pressurization capacities, cycling, and $\mathrm{V}_{\mathrm{T}}$ accuracy, especially in the presence of leaks. These observations might put the rationale of using PSV in the pediatric population into question and might also give insight into why the introduction of assisted ventilation modes did not show major advantages in terms of improved outcomes compared with controlled modes. ${ }^{25,30}$ Additionally, the poor ventilation performance documented with the currently available ventilators and the absence of an optimal ventilator for delivering PSV to small children must be taken into account when new ventilatory modes, such as Neurally Adjusted Ventilatory Assist, are compared with standard PSV. More specifically, the improved patient-ventilator synchrony documented with Neurally Adjusted Ventilatory Assist in recent studies $8,9,31-33$ could have been enhanced by the non-optimal ventilation performance of the ventilator used for PSV.

As optimizing the ETS criterion is difficult at the bedside, especially because respiratory mechanics and the amount of leakage often vary over time, ventilators should offer reliable tools to measure resistance and dynamic compliance (eg, by single-occlusion technique ${ }^{34}$ ) during ongoing mechanical ventilation and automatically adjust ETS based on this information. As NIV was shown to improve short-term outcomes in children, ${ }^{35}$ the use of this ventilation modality is probably going to increase in the near future, and ventilators must offer NIV algorithms that efficiently deal with the presence of leaks. Given the circumstances, it might be preferable to use time-cycled pressure modes to deliver NIV to small children, although these modes seem to increase trigger delay slightly. ${ }^{8}$ 
Concerning the pediatric and neonatal modes available on 2 of the ventilators tested (Fabian and Evita XL NeoFlow), we observed only a slight difference in trigger delays, but no significant differences in pressurization or cycling. Theoretically, the difference between the 2 modes is a different maximum peak inspiratory flow. Therefore, we do not have any explanation for this small difference. Advantages may be seen only with higher inspiratory efforts.

Relying on the $\mathrm{V}_{\mathrm{T}}$ displayed by the machine in the presence of leaks when the NIV mode is not activated might be misleading and could cause the clinician to underestimate the delivered $\mathrm{V}_{\mathrm{T}}$. This could lead to the delivery of a higher assist than expected and even to a situation of overassistance. This issue can be considered as a missing security feature for both neonatal and adult ventilators when used in neonates.

There are several limitations of this study. First, a bench test can simulate only a few well-defined and stable conditions, but cannot reflect the extent and complexity of true clinical scenarios, such as the variability of patients' efforts, which change almost breath by breath. ${ }^{9}$ However, bench tests allow comparison between ventilators due to the reproducible conditions. Second, a fixed ETS cannot be optimal for various clinical situations, and it could be argued that the value chosen for this study (15\%) was arbitrary. However, almost no data on an optimal cycling criterion in the pediatric setting are available in the literature. In our pediatric ICU, $10 \%$ is the most frequently used ETS during invasive ventilation. ${ }^{24}$ Interestingly, when a higher value of $25 \%$ (interquartile range of 21-29) was used during NIV, many premature cycling events were documented, suggesting that this threshold was too high even in the presence of leaks. As the Babylog VN500, a typical neonatal ventilator, has a non-modifiable ETS of only $15 \%$, we decided to use this same value to test all ventilators to allow comparisons between the machines. Of course, this choice can influence the $\mathrm{T}_{\mathrm{I}_{\mathrm{ex}}}$ we measured and the occurrence of late cycling documented in our bench test. Additionally, as the Leoni Plus has a non-modifiable ETS of $25 \%$, this ventilator could not be tested under the same conditions as the other ventilators, which means that the $T_{I_{\mathrm{ex}}}$ results reported for this ventilator must be considered with caution. Third, the inspiratory times we used in our bench tests were slightly higher than the values reported previously, especially for premature infants. However, as all ventilators were tested with the same inspiratory times, and as these values were not very different from those reported previously, in our opinion, this should not have significantly influenced our bench test results. Fourth, to take into account the low amplitude efforts occurring during sleep in small infants, we chose to simulate low inspiratory efforts in our bench test. As a consequence, we cannot conclude that we would have found the same results if higher inspiratory demands had been used. Finally, we did not evaluate all operational aspects of the ventilators, such as the user friendliness or the alarm settings, and their interaction with ventilation parameters. These important aspects should be the aim of a future study.

\section{Conclusions}

In our pediatric bench test, no ventilator performed equally well in all tested patient types and all tested leakage scenarios for all explored parameters (triggering, pressurization, cycling, and $\mathrm{V}_{\mathrm{T}}$ measurement accuracy), and we were not able to identify an optimal ventilator to deliver PSV in all tested situations to neonates and children. However, neonatal ventilators tended to perform better in the presence of air leaks.

As adult ventilators globally performed better in the presence of air leaks when NIV algorithms were activated, turning these algorithms on is suggested when these ventilators are used to deliver PSV through uncuffed tubes to neonates and young children. However, this recommendation is not valid for the Servo-i, as this ventilator performed poorly when its NIV algorithm was activated. In summary, we conclude that our findings emphasize the need to improve algorithms for assisted ventilation modes to better deal with situations of high airway resistance, low pulmonary compliance, and the presence of leaks.

\section{ACKNOWLEDGMENTS}

We thank Mr Vincent Mathes (Chur, Switzerland) for proofreading.

\section{REFERENCES}

1. Betensley AD, Khalid I, Crawford J, Pensler RA, DiGiovine B. Patient comfort during pressure support and volume controlled-continuous mandatory ventilation. Respiratory care 2008;53(7):897-902.

2. Futier E, Constantin JM, Combaret L, Mosoni L, Roszyk L, Sapin V, et al. Pressure support ventilation attenuates ventilator-induced protein modifications in the diaphragm. Crit Care 2008;12(5):R116.

3. Greenough A, Dimitriou G, Prendergast M, Milner AD. Synchronized mechanical ventilation for respiratory support in newborn infants. Cochrane Database Syst Rev 2008;(1):CD000456.

4. Vignaux L, Tassaux D, Carteaux G, Roeseler J, Piquilloud L, Brochard L, Jolliet P. Performance of noninvasive ventilation algorithms on ICU ventilators during pressure support: a clinical study. Intensive Care Med 2010;36(12):2053-2059.

5. Vignaux L, Vargas F, Roeseler J, Tassaux D, Thille AW, Kossowsky MP, et al. Patient-ventilator asynchrony during non-invasive ventilation for acute respiratory failure: a multicenter study. Intensive Care Med 2009;35(5):840-846.

6. Bernstein G, Knodel E, Heldt GP. Airway leak size in neonates and autocycling of three flow-triggered ventilators. Crit Care Med 1995; 23(10):1739-1744.

7. Marchese AD, Chipman D, de la Oliva P, Kacmarek RM. Adult ICU ventilators to provide neonatal ventilation: a lung simulator study. Intensive Care Med 2009;35(4):631-638. 


\section{ICU Ventilators for NeONATES, INFANTS, AND ChILDREN}

8. Bordessoule A, Emeriaud G, Morneau S, Jouvet P, Beck J. Neurally adjusted ventilatory assist improves patient-ventilator interaction in infants compared to conventional ventilation. Pediatr Res 2012;72(2): 194-202.

9. de la Oliva P, Schüffelmann C, Gómez-Zamora A, Villar J, Kacmarek RM. Asynchrony, neural drive, ventilatory variability and COMFORT: NAVA versus pressure support in pediatric patients. A non-randomized cross-over trial. Intensive Care Med 2012;38(5): 838-846.

10. Battisti A, Tassaux D, Janssens JP, Michotte JB, Jaber S, Jolliet P. Performance characteristics of 10 home mechanical ventilators in pressure-support mode: a comparative bench study. Chest 2005; 127(5):1784-1792.

11. Tassaux D, Strasser S, Fonseca S, Dalmas E, Jolliet P. Comparative bench study of triggering, pressurization, and cycling between the home ventilator VPAP II and three ICU ventilators. Intensive Care Med 2002;28(9):1254-1261.

12. Vignaux L, Tassaux D, Jolliet P. Performance of noninvasive ventilation modes on ICU ventilators during pressure support: a bench model study. Intensive Care Med 2007;33(8):1444-1451.

13. Aslanian P, El Atrous S, Isabey D, Valente E, Corsi D, Harf A, et al. Effects of flow triggering on breathing effort during partial ventilatory support. Am J Respir Crit Care Med 1998;157(1):135-143.

14. Whitelaw WA, Derenne JP, Milic-Emili J. Occlusion pressure as a measure of respiratory center output in conscious man. Respir Physiol 1975;23(2):181-199.

15. Carteaux G, Lyazidi A, Cordoba-Izquierdo A, Vignaux L, Jolliet P, Thille AW, et al. Patient-ventilator asynchrony during noninvasive ventilation: a bench and clinical study. Chest 2012;142(2):367-376.

16. Piquilloud L, Tassaux D, Bialais E, Lambermont B, Sottiaux T, Roeseler J, et al. Neurally adjusted ventilatory assist (NAVA) improves patient-ventilator interaction during non-invasive ventilation delivered by face mask. Intensive Care Med 2012;38(10):1624-1631.

17. Vignaux L, Tassaux D, Jolliet P. Evaluation of the user-friendliness of seven new generation intensive care ventilators. Intensive Care Med 2009;35(10):1687-1691.

18. Fauroux B, Leroux K, Desmarais G, Isabey D, Clément A, Lofaso F, Louis B. Performance of ventilators for noninvasive positive-pressure ventilation in children. Eur Respir J 2008;31(6):1300-1307.

19. Harikumar G, Moxham J, Greenough A, Rafferty GF. Measurement of maximal inspiratory pressure in ventilated children. Pediatr Pulmonol 2008;43(11):1085-1091.

20. Honma Y, Wilkes D, Bryan MH, Bryan AC. Rib cage and abdominal contributions to ventilatory response in $\mathrm{CO} 2$ in infants. J Appl Physiol Respir Environ Exerc Physiol 1984;56(5):1211-1216.

21. Curzi-Dascalova L, Peirano P, Morel-Kahn F. Development of sleep states in normal premature and full-term newborns. Dev Psychobiol 1988;21(5):431-444.

22. Nicolai T. Mini-symposium: lung physiology. The physiological basis of respiratory support. Pedriatr Respir Rev 2006;7(2):97-102.
23. Beck J, Reilly M, Grasselli G, Mirabella L, Slutsky AS, Dunn MS, Sinderby C. Patient-ventilator interaction during neurally adjusted ventilatory assist in low birth weight infants. Pediatr Res 2009;65(6): 663-668.

24. Vignaux L, Grazioli S, Piquilloud L, Bochaton N, Karam O, Jaecklin $\mathrm{T}$, et al. Optimizing patient-ventilator synchrony during invasive ventilator assist in children and infants remains a difficult task. Pediatr Crit Care Med 2013;14(7):e316-e325.

25. Greenough A. Comparison between intermittent mandatory and synchronized intermittent mandatory ventilation with pressure in children. J Pediatr 2009;85(1):1-3

26. Tokioka H, Tanaka T, Ishizu T, Fukushima T, Iwaki T, Nakamura Y, Kosogabe Y. The effect of breath termination criterion on breathing patterns and the work of breathing during pressure support ventilation. Anesth Analg 2001;92(1):161-165.

27. Calderini E, Confalonieri M, Puccio PG, Francavilla N, Stella L, Gregoretti C. Patient-ventilator asynchrony during noninvasive ventilation: the role of expiratory trigger. Intensive Care Med 1999; 25(7):662-667.

28. Jaecklin T, Morel DR, Rimensberger PC. Volume-targeted modes of modern neonatal ventilators: how stable is the delivered tidal volume? Intensive Care Med 2007;33(2):326-335.

29. Mahmoud RA, Fischer HS, Proquitté H, Shalaby HM, Schmalisch G. Relationship between endotracheal tube leakage and under-reading of tidal volume in neonatal ventilators. Acta Paediatr 2009;98(7): 1116-1122.

30. Moraes MA, Bonatto RC, Carpi MF, Ricchetti SM, Padovani CR, Fioretto JR. Comparison between intermittent mandatory ventilation and synchronized intermittent mandatory ventilation with pressure support in children. J Pediatr 2009;85(1):15-20.

31. Alander M, Peltoniemi O, Pokka T, Kontiokari T. Comparison of pressure-, flow-, and NAVA-triggering in pediatric and neonatal ventilatory care. Pediatr Pulmonol 2012;47(1):76-83.

32. Breatnach C, Conlon NP, Stack M, Healy M, O'Hare BP. A prospective crossover comparison of neurally adjusted ventilatory assist and pressure-support ventilation in a pediatric and neonatal intensive care unit population. Pediatr Crit Care Med 2010;11(1):7-11.

33. Clement KC, Thurman TL, Holt SJ, Heulitt MJ. Neurally triggered breaths reduce trigger delay and improve ventilator response times in ventilated infants with bronchiolitis. Intensive Care Med 2011;37(11): 1826-1832.

34. Katier N, Uiterwaal CS, de Jong BM, Kimpen JL, van der Ent CK. Feasibility and variability of neonatal and infant lung function measurement using the single occlusion technique. Chest 2005;128(3): 1822-1829.

35. Najaf-Zadeh A, Leclerc F. Noninvasive positive pressure ventilation for acute respiratory failure in children: a concise review. Ann Intensive Care 2011;1(1):15.

This article is approved for Continuing Respiratory Care Education credit. For information and to obtain your CRCE

(free to AARC members) visit www.rcjournal.com

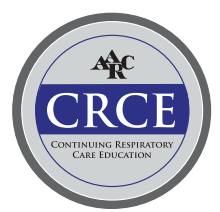

